\title{
REFLEXIONES SOBRE LA HISTORIA Y LA CULTURA ALTEÑAS
}

GENARO ZALPA RAMÍREZ

Departamento de Sociologia/UAA

VARIOS AUTORES, Aguascalientes y Los Altos de Jalisco: historia compartida, Guadalajara, El Colegio de Jaliscol Gobierno del Estado de Aguascalientes, 1997, 108 pp.

Nos s dice Andrés Reyes que el origen del libro que comentamos es un coloquio que se organizó para que los investigadores interesados en las historias de Aguascalientes y de Los Altos intercambiaran sus ideas y sus experiencias, buscando encontrar relaciones entre estas dos regiones, dada su cercanía geográfica, económica, social y cultural. El evento tuvo lugar en septiembre de 1996.

Supongo que se decidió dar a ese intercambio de ideas el nombre de coloquio, en lugar del más formal de panel, por ejemplo, para sugerir precisamente un intercambio más informal, más casero, entre amigos, de las ideas que a cada es- tudioso le habían ido surgiendo acerca de la relación entre Los Altos y Aguascalientes a partir de su experiencia como investigadores de los fenómenos históricos de una o de otra región, o de ambas. Me refiero a esa clase de ideas que, en el curso de investigaciones que tienen otros objetivos, aparecen una vez y otra hasta que, en algunos casos, se convierten a su vez en objetivos de investigación, pero que, en otros casos, quedan como ideas apenas esbozadas, pero que, de todos modos, uno quiere compartir. Me imagino que el coloquio debe haber sido muy rico en intercambios de ideas, y me alegra que los participantes, al decidir publicar sus intervenciones, nos hayan invitado, a todos los lectores, a participar también en el coloquio, a platicar las ideas que sus trabajos nos han sugerido.

Me voy a permitir crear, en esta presentación, mi propio coloquio imaginario. 
Es decir, voy a recrear una conversación imaginaria entre los autores del libro. Y en este coloquio imaginario, enarbolando el derecho que dice Umberto Eco que tenemos todos los lectores, me voy a permitir meter mi propia cuchara. Desde luego, toda semejanza con el coloquio real será pura coincidencia.

Mi primera intervención, en forma de pregunta, se refiere al mercado laboral en Aguascalientes y en Los Altos en el siglo XVII, que es el título y el tema tratado por José Antonio Gutiérrez. Si, como lo afirman José María Muriá y el propio José Antonio, casi no quedaron indios en la región después de las guerras del Miztón (Por cierto, ¿Mizton, como lo escribe Muriá, o Mixtón, como lo escribe José Antonio, o da lo mismo?) y la guerra Chichimeca, y si esto hizo que los colonizadores de estas regiones -que no eran los colonizadores convencionales, los hijosdalgo dispuestos a todo menos a trabajar, como lo afirma Muriá-, a diferencia de lo que sucedió en otras regiones de la Nueva España, trabajaran ellos mismos sus tierras, ¿por qué tiene importancia el mercado del trabajo en la región? La pregunta se enfatiza si generalizamos en el tiempo y en el espacio la afirmación que, para la segunda mitad del siglo XVIII y la primera del XIX, hace Celina Guadalupe Becerra, de que el número de los mulatos y los grupos de sangre mezclada tienen una presencia numérica modesta en el centro de Los Altos, por lo que no podían ser estos grupos los que aportaran trabajadores para la región. ¿¿No podríamos, más bien, concluir que en estas regiones no se dio un mercado de trabajo como se dio en otras regiones de la Nueva España?

Jesús Gómez señala como causales del fraccionamiento de la gran propiedad en Aguascalientes, durante la primera mitad del siglo XIX, las dificultades económicas producidas por la guerra de independencia que hicieron que estas propiedades se cargaran de deudas, y los pleitos entre compradores, vendedores, acreedores y familiares. Pone los ejemplos de San Diego de la Labor, Paredes, Pabellón, Peñuelàs, y otros casos que dice que no tiene suficientemente documentados. ¿No tendría algo que ver también la escasez de mano de obra para acrecentar las dificultades que llevaron al fraccionamiento de la gran propiedad en Aguascalientes y la región? En todo caso, en consonancia con Jesús, que señala el surgimiento de los rancheros como efecto de este fraccionamiento, Muriá, Yolanda Padilla y otros investigadores hacen notar que los postulados agraristas de la revolución, y el movimiento agrario postrevolucionario se encontraron en Los Altos y en Aguascalientes con una propiedad ya fracciona- 
da, con rancheros dueños de sus propias tierras. Muriá señala este hecho como uno de los factores explicativos de la Cristiada. Para completar la reflexión, Yolanda Padilla se pregunta si se puede establecer relación entre pequeña propiedad, autonomía y religión en Los Altos, en contraposición al ejido, dependencia y estatismo.

Con la exposición de Celina Guadalupe Becerra acerca de las costumbres matrimoniales en la parroquia de Jalostotitlán a fines del siglo XVIII y principios del XIX, pasamos a un terreno que me es más familiar, y que me permitirá meter más mi cuchara, el de la cultura. En una síntesis que no hace justicia a la exposición original, la autora nos dice que los españoles criollos acostumbraban, por lo general, casarse entre sí, para lo cual tenían que recurrir frecuentemente a matrimonios entre parientes. En el otro extremo, los indígenas también practicaban la endogamia, aunque la autora no dice si, igualmente, dado su escaso número, recurrían al matrimonio entre parientes. Resulta sorprendente que fueran los mulatos los que, en un mayor porcentaje, realizaran matrimonios mixtos, sobre todo si se tiene en cuenta que, como dice Muriá, en Los Altos hasta los indios son güeros. La autora enfatiza la endogamia geográfica, que significa que los alteños se casan con alteños, lo que, metiendo mi cuchara. también puede interpretarse como una endogamia cultural que, cerrando el círculo, permite la reproducción de la cultura alteña, algunos de cuyos rasgos señalan tanto Muriá como Yolanda. De estos rasgos me interesa resaltar los que se refieren al tipo de relaciones familiares, lo que me permitirá exponer, a mí también. una de esas ideas que a uno se le ocurren leyendo material como el que se encuentra en el libro: En su estudio sobre las relaciones de parentesco, al tratar de las relaciones especiales que en algunas sociedades se establecen entre el tío materno y el sobrino, Lévi-Strauss dice que las relaciones familiares no son sólo un sistema de nomenclatura, sino también un sistema de actitudes que se sintetizan en la oposición autoritario/afectivo. Si, por economía, asignamos el signo + a las relaciones afectivas y el signo - a las relaciones autoritarias, y tipificamos con estos signos las relaciones familiares en la cultura alteña, podemos, quizá, encontrar el sistema de actitudes y sus transformaciones. Tendríamos, entonces, en la familia alteña el siguiente sistema:

Las relaciones entre esposo y esposa son relaciones autoritarias o, por lo menos, de poca demostración afectiva. Las relaciones entre los padres y los hijos son relaciones autoritarias. Aquí cabría la 
observación de Muriá de que también la madre ejerce la autoridad en la familia, aunque esto no contradice el machismo, como él lo supone, porque la autoridad de la madre se ejerce con los hijos, mientras que la mujer permanece subordinada al hombre. No sabría cómo calificar las relaciones entre los hermanos. Por una parte debe ser de familiaridad y afecto, pero por otra las hermanas están sujetas a la autoridad de los hermanos. Quizá haya que distinguir las relaciones de los hermanos varones entre sí y las de las hermanas mujeres entre sí de las relaciones entre los hermanos y las hermanas.

En toda familia, dice Lévi-Strauss, entra también un componente extra familiar, representado por un miembro de otra familia que entra, o puede entrar, en relación de parentesco por matrimonio. En este caso se me ha hecho notar que, mientras que hasta el momento de la boda misma el novio o esposo de las hijas de un padre alteño es visto como enemigo, después de la boda se establece una relación de más confianza entre suegro y yerno que entre padre e hijos.

Valdría la pena investigar cómo los rasgos culturales relativos a los tipos específicos de relaciones entre los miembros de la familia se van modificando cuando los, o las alteñas se unen en matrimonio con los no alteños.
Yolanda Padilla nos describe algunos rasgos de la religiosidad alteña, y cómo algunos van cambiando cuando se insertan en el ritmo de vida de una ciudad como Aguascalientes. Describe el catolicismo alteño como tradicional y asociado a ciertas prácticas religiosas como la frecuencia de los sacramentos y otras prácticas como el rezo del rosario en familia y la observación del recogimiento y la asistencia a ejercicios durante la cuaresma, así como la devoción a los santos patronos. También nos describe cómo esta religiosidad se va transformando cuando los alteños viven en una ciudad como Aguascalientes. Sin embargo, hay un rasgo que está presente, pero tal vez no suficientemente estudiado, que es el carácter beligerante de este catolicismo, que se manifestó en la Cristiada y que, como lo dice la autora, a pesar de la transformación de la religiosidad está presto a aflorar a la menor provocación, como lo demuestra el conflicto intraeclesial que se vivió en Aguascalientes en los años setenta.

José María Muriá hace un inventario de rasgos culturales de los alteños: son patas de perro pero apegados a su tierra, $y$ los que emigran principalmente son los hombres. Las mujeres educan a los hijos y administran el hogar y los bienes familiares; cuando es necesario, aportan a la economía familiar. Los alteños son aho- 
rradores, parcos con los dineros y con una perseverancia rayana en la terquedad. Esta terquedad los ha hecho continuar dedicándose a la ganadería, sobre todo lechera, cuando las tierras no son adecuadas y los márgenes de ganancia son mínimos. Otra de sus ocupaciones características es el comercio. Para los alteños la palabra empeñada es más vinculante que la firma de documentos. Son hospitalarios y reservados al mismo tiempo, y con cierta tendencia a la endogamia. A estos rasgos podríamos agregar los que Yolanda toma del plan diocesano de pastoral de la diócesis de Aguascalientes: identidad cultural confundida con su identidad religiosa, seguridad en su cultura, machismo inserto en una familia autoritaria, mentalidad ranchera, calendario festivo relacionado con el ciclo agrícola temporal y cultura condicionada por la emigración a los Estados Unidos.

Finalmente, María Guadalupe Rodríguez nos expone cómo han enfrentado los ganaderos de Los Altos y de Aguascalientes, casi todos culturalmente alteños, el reto de la globalización reflejado en la exigencia de calidad en la producción de la leche. Esta exigencia se traduce, en concreto, en la necesidad de los pequeños productores de unirse para comprar tanques de enfriamiento. La autora nos relata cómo, por un lado, algunos produc- tores han comprendido esta exigencia y, de hecho, se han unido para responder a la exigencia de calidad, y cómo, por otro lado, algunos productores, en base a una racionalidad económica que tiene en cuenta costos y ganancias, se han resistido a unirse para invertir en los tanques de enfriamiento. Este artículo nos hace caer en la cuenta de otros dos rasgos de la cultura alteña: la racionalidad y el individualismo económicos.

Estos tres últimos artículos que he sintetizado me permiten, metiendo de nuevo mi cuchara en el coloquio, replantear mi idea de que los alteños comparten una cultura que, a pesar de su acendrado catolicismo, está muy cercana de la ética protestante anglosajona descrita por Max Weber. Rasgos de la cultura alteña como el valor del trabajo de hombres y mujeres, la tendencia al ahorro, la racionalidad económica que tan claramente se manifiesta en las entrevistas realizadas por la investigadora que se interesó en el problema de la calidad de la leche, el valor de la palabra en los tratos comerciales y hasta la creencia en un origen celta o francés y la endogamia, nos harían concluir claramente que sí, que los alteños comparten una cultura similar a la blanca, anglosajona y protestante que se derivó de la ética calvinista. Pero hay, evidentemente, rasgos que no concuerdan. Para 
empezar, el catolicismo apasionado, beligerante, que tan bien documenta Yolanda Padilla, y otros rasgos que se derivan de este catolicismo y que los investigadores no hicieron notar como la caridad y la compasión, y, paradójicamente, la prodigalidad en ciertas circustancias, particularmente en las fiestas familiares, así como la afición a la comida, al alcohol y las apuestas.

Me atrevo, entonces, a lanzar la hipótesis de una ética-católica-alteña, derivada de una manera de entender y vivir el catolicismo que es específica de los habitantes de esta región de Jalisco y de gran parte de Aguascalientes, y que ayudaría a entender, tanto la historia como el presente económico, político y social de esta región.

Pongo sólo un ejemplo que, a primera vista, a mí mismo me parece un poco, por decir lo menos, atrevido, pero que tal vez se pudiera fundamentar: Muriá hace notar que Los Altos no tiene una cabecera reconocida, que los alteños se relacionan con Guadalajara, con León y con Aguascalientes, y que en algunas ocasiones han considerado la idea de formar parte de este último estado. Yo había escuchado, por otra parte, que la parte norte del estado de Aguascalientes es la menos alteña del estado y que, específicamente, Pabellón de Arteaga, como población relativa- mente reciente, creada a la sombra de los planes gubernamentales relacionados con el movimiento agrarista, es la antítesis de lo alteño. Parafraseando a Yolanda: ejidal, dependiente y estatista. ¿No será, entonces, que a los factores que consideren los análisis, todavía por hacer, de los resultados de las últimas elecciones tengamos que añadir el componente cultural? Por un lado un candidato de origen alteño (Felipe González) a quien la población le atribuye las características de esa cultura: católico, comerciante, trabajador, honesto, etc., y por el otro a un candidato (Héctor Hugo Olivares), de origen pabellonense, no muy católico -si es que lo es-, agrarista, que se ha hecho a la sombra del estado, con sospechas de deshonestidad, etc. Si esto fuera cierto, para calificar en términos alteños la contundente victoria de Felipe González tendríamos que decir que los votantes de Aguascalientes concluyeron: " $\mathrm{Pa}$ ' los toros del jaral, los jinetes de allá mesmo".

Termino con dos invitaciones, una a la lectura de este interesante y estimulante libro, y otra a la realización de más coloquios como el que le dio origen y, también, al debate y la discusión académicas. Después de todo, también se llama coloquio, en las pastorelas, al debate entre el diablo y San Miguel. 